January 2013

\title{
Information Literacy Instruction for Upper-Year Undergraduate Students: A Stratified Course-Integrated Approach
}

Stacey Nordlund

San José State University, staceynordlund@gmail.com

Follow this and additional works at: https://scholarworks.sjsu.edu/ischoolsrj

Part of the Library and Information Science Commons

\section{Acknowledgements}

This article developed from a research paper I wrote for Michelle Holschuh Simmons' graduate seminar in Information Literacy at San José State University's School of Library and Information Science. I would like to thank Dr. Simmons for her feedback and support.

\section{Recommended Citation}

Nordlund, S. (2013). Information Literacy Instruction for Upper-Year Undergraduate Students: A Stratified Course-Integrated Approach. School of Information Student Research Journal, 2(2). https://doi.org/ 10.31979/2575-2499.020204 Retrieved from https://scholarworks.sjsu.edu/ischoolsrj/vol2/iss2/4

This article is brought to you by the open access Journals at SJSU ScholarWorks. It has been accepted for inclusion in School of Information Student Research Journal by an authorized administrator of SJSU ScholarWorks. For more information, please contact scholarworks@sjsu.edu. 


\title{
Information Literacy Instruction for Upper-Year Undergraduate Students: A Stratified Course-Integrated Approach
}

\author{
Abstract \\ Undergraduate students face many potential barriers to learning about the process of conducting \\ research. Information literacy instruction provided through faculty-librarian collaboration in an effort to \\ expand the abilities of the "novice researcher" can ease the experience of undergraduate students. In \\ addition, information literacy instruction may invoke increased student participation in the scholarly \\ discourse of their chosen discipline. The implementation of a stratified course-integrated approach may \\ be particularly valuable to upper-level undergraduates in preparation for completing a thesis or other \\ culminating project in their final year of study. This claim is examined within the context of an instruction \\ session observed as a component of a third-year undergraduate Materials Science and Engineering \\ course.
}

\section{Keywords}

information literacy, academic libraries, undergraduate, course-integrated instruction, faculty-librarian collaboration

\section{Acknowledgements}

This article developed from a research paper I wrote for Michelle Holschuh Simmons' graduate seminar in Information Literacy at San José State University's School of Library and Information Science. I would like to thank Dr. Simmons for her feedback and support.

\section{About Author}

Stacey Nordlund is a recent graduate of the MLIS program at San José State University and holds a BS in Psychology from the University of Toronto. She works as a reference librarian for the Toronto Public Library in Toronto, Ontario, and volunteers as a virtual reference librarian for Ask Ontario. 


\section{Information Literacy Instruction for Upper-Year Undergraduate Students: A Stratified Course-Integrated Approach}

In our current information economy, it is critical to develop information literacy (IL) skills for success as students, as professionals, and in everyday life, in order to navigate the world as informed citizens. Library and information science (LIS) literature over the last century features much lively discussion about IL instruction: what form should it take, and who should be responsible for the instruction? Gunselman and Blakesley (2012) provide an excellent summary of seminal articles that have explored these questions; however, there are no definitive conclusions and the debate persists. The only consensus reached is that IL is an essential skill. The ability to plan and develop IL instruction lessons and programs is, therefore, a crucial skill for librarians to possess, regardless of the information environment in which they practice. IL instruction is particularly germane to the work of academic librarians, who are tasked with helping undergraduate and graduate students develop critical information literacy skills.

Students face a number of potential barriers to learning when they are initially introduced to the research process at the undergraduate level. One of these barriers is indirectly caused by the disconnect between faculty members and undergraduates, who reside at opposite ends of the educational spectrum. Faculty members might assign the task of completing a research paper to first-year students without initially consulting librarians about the most effective way of integrating this type of assignment into the curriculum, and without giving consideration to students' ability to successfully identify and research a topic. To address this problem, Leckie (1996) suggests restructuring the traditional research paper assignment that is often assigned to first-year undergraduates. She proposes a six-step stratification process in which faculty members guide their students through the research process by developing multiple assignments and by placing these assignments within a particular disciplinary context.

This article will describe Leckie's stratified course-integrated model of providing IL instruction. It is proposed that the use of Leckie's model as an IL instruction framework be examined for potential application beyond its suggested use with first-year undergraduate classes. Instead, it may be consistently applied in classes across the span of an undergraduate education, with a particular emphasis on upper-year undergraduate classes, in order to maximize student learning and to help students meet the competency standards as codified in the Information Literacy Competency Standards for Higher Education (Association of College and Research Libraries, 2000). The present exploratory research uses findings gleaned from observation and interviews to support the assertion that IL programs may benefit from a stratified course-integrated approach, particularly 
for upper-level undergraduates preparing for a thesis or other culminating project in their final year of study.

\section{Literature Review}

There is a dearth of studies in the literature that examine course-integrated library instruction conducted specifically within a framework of stratification. This is an area that requires a closer look in order to gain additional insight into effective teaching and curriculum development. As noted in the introduction, it is debated whether IL instruction falls under the purview of faculty members' or librarians' work (or both), and is therefore an important area of study in LIS research. Mahaffy (2006) provides an excellent summary of sample assignments that are designed to stimulate critical thinking and reflect the Information Literacy Competency Standards for Higher Education (Association of College and Research Libraries, 2000). Mahaffy makes a brief mention of the importance of making library instruction relevant to the students' coursework using a stratified system:

Effective assignments, therefore, are woven into the fabric of the course design, simultaneously furthering the student's information-literacy skills and his [or her] knowledge of the subject matter. The instructor may find this easier to master by designing a series of smaller assignments that students work on throughout the semester rather than relying on one major paper as a final project. (p. 326-327)

Although there is infrequent discussion of stratified course-integrated models of IL instruction specifically, the development of course-integrated IL instruction in undergraduate education continues to be greatly discussed in the scholarly literature. There are two main themes that stand out in academic discourse on this topic: the impact of faculty-librarian collaboration, and the idea of "bridging the gap" between faculty members' and students' contrasting approaches to the research process.

\section{Librarian-Faculty Collaboration}

Collaboration between librarians and faculty members is essential in order for stratified course-integrated IL instruction to succeed. Much scholarly attention has been paid to the benefits afforded to participation in librarian-faculty collaborative relationships. There is also a great deal of commentary regarding the challenges inherent in developing partnerships between these two groups. As Given and Julien (2005) note, although faculty members and academic librarians are both 
engaged in pursuing a similar goal (educating students), there are many differences in the steps they take as they pursue these objectives. These differences can result in conflict between faculty members and librarians.

For example, Given and Julien (2005) undertook a content analysis of messages posted to an active listserv for librarians (BI-L [ILI-L]) to determine librarian attitudes toward librarian-faculty relationships. Although some librarianwriters were generous, many of the comments and attitudes posted by librarians with regard to faculty were negative in tone. In addition, many of the librarianwriters felt that faculty members did not accord librarians enough respect. Given and Julien suggest that librarians should first recognize and acknowledge that faculty members and academic librarians are "masters of their own (separate but related) spheres" (p. 36), and should also respect the faculty members' position in order to develop improved relationships with faculty.

Of course, it is evident that the reverse is true as well: faculty members should respect the efforts of librarians as the librarians strive to enter into collaborative relationships with faculty. Collaboration cannot succeed unless faculty members are open to devoting class time to the purpose of developing IL skills. However, many faculty members feel the pressure of time constraints and are therefore resistant to taking time away from the course content in an effort to devote class time to this purpose (Feldman \& Sciammarella, 2000). Leckie and Fullerton's (1999) interviews with science and engineering faculty revealed faculty perceptions that the disciplinary knowledge those faculty cover in a semester is so extensive that there is little room on the syllabus for lessons involving "frills" (p. 22) such as IL instruction. Instead of aggressively foisting IL instruction on faculty members who are already feeling pressured, librarians should instead approach discussions with faculty by articulating how IL instruction and librarian involvement in classes will yield greater benefits for both faculty and students.

The collaborative relationship between teaching faculty and librarians may also be affected by a perceived power imbalance between the two groups. Julien and Pecoskie (2009) interviewed 56 librarians and paraprofessionals with instructional responsibilities in academic and public libraries and discovered a common pattern of "deference discourse" (p. 151) in the discussion of participants' relationships to teaching faculty. A power imbalance, either real or perceived, can increase the challenge of improving IL instruction programs since, rather than maintaining a focus on students, librarians are distracted by navigating their relationships with faculty members.

Collaboration should be entered into cooperatively. Farber (1999) describes the ideal cooperative relationship between librarians and teachers as "mutually reinforcing" (p. 233). In cooperative relationships, the aim is that the teacher's objective to help students gain a comprehensive understanding of a 
subject and the librarian's objective to help students find and evaluate information are both met. Simmons (2005) also recommends a cooperative approach in which both the librarian and the faculty member work together. Simmons notes that this collaboration is intended to lead the students into a discourse community in which the student is able to gain an understanding of the breadth of disciplinary research from the librarian. At the same time, the student is able to grasp the depth of the specific practices of a discipline from the faculty member.

Beyond the issues relating to faculty-librarian attitudes are larger, systemic concerns. Even if faculty and librarians actively seek to collaborate and create an IL-based partnership, there may be difficulties in implementing programs. One way of increasing collaborative opportunities is by developing what Stowe (2011) terms "curriculum-integrated library instruction" (p. 84). This type of instruction involves a continuum of instruction for students. The instruction develops over the course of a four-year university degree with increasing complexity as the students progress through their courses. The goal is to design and establish a program that is "both immediately relevant and progressively challenging in building a foundation for students in critical thinking and lifelong learning" (p. 82).

In 2010, the Brooklyn Campus of Long Island University added library instruction as a component of two classes in their English department, with the aim of gradually integrating IL instruction across a full range of required English composition courses. This program was developed through a partnership between the library and the English department, but faced a number of challenges due to budgetary restrictions and personnel issues caused by a library hiring freeze (Stowe, 2011). These restrictions may become more commonplace given the current economic climate. However, preliminary feedback from all participantslibrarians, faculty members, and students - appears positive and the program was being incorporated into additional classes over the 2011-2012 academic year for continued assessment.

A more recent example of successful IL instruction program focusing on faculty-librarian collaboration is the Coates Library of Trinity University. Oakleaf, Millet, and Kraus (2011) performed a case study of the Coates Library IL program, in which an emphasis on improving campus engagement in IL instruction started almost a decade ago has subsequently resulted in a significant increase in course-integrated library instruction. One consequence of this increased instruction was more frequent communication between faculty and librarians as well as an increase in faculty viewing "librarians as educational partners" (p. 834). A similar collaborative approach was undertaken at The College of New Jersey, in which the chemistry faculty and chemistry librarian shared knowledge, experiences, and goals for student learning in the creation of the Chemistry Seminar Program, an IL instruction program consisting of two one- 
hour seminars for freshman, sophomore, and junior chemistry undergraduates (Tucci, 2011). Tucci notes that "traditional boundaries that limited the interactions of the subject librarian and the faculty were disregarded and the librarian became a valued partner with faculty" (p. 303). Therefore, one solution to difficulties experienced in faculty-librarian relationships may be to increase the frequency of contact between these two groups by creating opportunities for increased collaboration on projects with specific goals.

\section{Bridging the Gap from Novice to Expert}

The second theme to be considered is the existence of a chasm separating the faculty member as "expert researcher" from the student as "novice researcher" (Leckie, 1996, p. 202). Leckie suggests that faculty members are independent researchers who have developed their own personal information-seeking strategies, and who have achieved their status through a process of acculturation, extensive knowledge of their discipline, awareness of important names in the field, participation in informal scholarly discourse, a view of research as a process in which the journey is intuitive rather than entirely straightforward, and a bit of luck. This model depicts a series of characteristics that are quite different from those possessed by the average undergraduate student.

The student model, as proposed by Leckie (1996), paints the undergraduate as an untrained, relatively blank slate. The student has not conducted enough research to have developed a personal information-seeking strategy, possesses very little disciplinary knowledge, is unaware of important names in the field, is not part of a scholarly network, and views research as a "fuzzy library-based activity" (p. 203) (or likely Internet-based, now) that is required for homework completion. Simmons (2005) notes that the undergraduate student is poised to learn the specific discourse of the discipline they choose to study (i.e., beyond the general academic discourse applicable to all disciplines). Because the faculty member is so immersed in the scholarship of the discipline, the academic librarian is therefore instrumental in providing this type of instruction.

Not only is there the problem of a chasm between faculty and student understanding of the research process, but many faculty members are unaware of precisely the size of the gap between the two sides. Kolowich (2011) notes that professors may overestimate the research skills of their students and may not require students to confer with librarians before embarking on a research project. In an exploratory study of interview transcripts of faculty members and subject librarians from the disciplines of sociology and civil engineering, McGuinness (2006) found evidence of a tacit assumption among faculty that students will naturally yet haphazardly develop IL skills and that IL instruction does not need 
to be explicitly stated as part of the curriculum. The development of IL skills was not seen as a priority; rather, the acquisition of these skills was considered a natural, intuitive process that occurs as the student progresses through an undergraduate program. Leckie and Fullerton's (1999) interviews with science and engineering faculty revealed that a very large number of faculty admit having "a poor understanding of how students learn to do library-based research" (p. 14), with the most common thinking that "students somehow learned to do this on their own" (p. 15). Another common faculty perception was that undergraduates who had not learned to successfully conduct library-based research by their upper years were "unmotivated, uninterested, or just poor students" (Leckie and Fullerton, 1999, p. 15). More recently, Raven (2012) discovered a considerable gulf between student and faculty research expectations in a survey of first-year undergraduates and their instructors, and, most strikingly, found that very few of the survey participants believed that librarians should be "responsible for firstyear students learning how to do research" (p. 9). Instead, students were evenly divided between believing either instructors or students themselves should be responsible for developing this skill, whereas $80 \%$ of instructors felt that students were solely responsible for their developing their research abilities.

The chasm between the faculty and student mental models demonstrates the clear importance of conducting research that examines and assesses IL instruction from the student perspective. Such research may provide insight into the best methods of integrating IL instruction into the curriculum. Head (2008) compiled data from focus groups and a student survey about the ways students conceptualize and operationalize academic research. The population used for the study consisted of upper-division undergraduate students majoring in humanities and social sciences. This population was specifically selected because it was assumed that upper-year students would have more experience with the secondary research process than would first- or second-year students.

Interestingly, the results from the discussions and surveys indicate that upper-division undergraduate students experience difficulty in "limiting the scope of a research topic and dealing with the inevitable information overload that accompanies new forms of digital media" (Head, 2008, p. 433). In addition, Head found that students generally initiate the research process by accessing "nearby and convenient resources" (p. 434) such as a textbook or other assigned class readings. These third- and fourth-year students experienced many of the same challenges and emotional responses faced by first-year students when asked about their research process. Many of the students experienced feelings of being overwhelmed by information overload and an inability to narrow down a topic and make it manageable.

Head (2008) also examined the handouts provided by faculty members that listed assignment requirements. The content analysis she performed based on 
the information included on these handouts gleaned some findings that correlate with the model of faculty member as "expert researcher." The handouts offered little direction about how to plot a research course, how to craft a high quality paper, or how to prepare a paper that adheres to a specific grading rubric. Correspondingly, the surveyed students responded that a lack of information from instructors was their biggest challenge in beginning an assignment. This study's results are clearly indicative of the importance of continuing to provide research support to students even as they progress through their final year of their undergraduate education. This is an area in which faculty-librarian collaboration in cooperatively developing long-term IL instruction may be instrumental.

The difference between the research process of scholars and that of undergraduate students, and ideas for leading the students to develop the skills necessary for bridging this gap, has also been studied by Bodi (2002). Bodi notes that a research paper is an excellent tool that allows students to "exercise the qualities of analysis, synthesis, and evaluation" (p. 111). Bodi proposes a research model that embraces flexibility, yet maintains three key components: find a research topic, understand the difference between searching techniques (e.g., keywords vs. controlled vocabulary), and evaluate the quality of sources. She claims that librarians tend to invoke procedural, linear, step-by-step instruction, but that because the research process itself is interactive and circular, the traditional mode of instruction is not appropriate. Her claims seem strongly worded, particularly since she does not provide any sources as evidence; however, Bodi does temper the statement by noting the importance of collaboration between faculty, librarians, and students to improve student research papers.

The practice of integrating library instruction into the curriculum has also yielded positive results with second-year medical students. Minchow, Pudlock, Lucas, and Clancy (1993) found that incorporating information management skills into the curriculum within the context of problem-based learning resulted in increased learning for students: "Formal library instruction was not in itself sufficient to provide the information skills for their needs. Integration of information-seeking skills into the curriculum in a directed sequence of assignments reinforced the applicability of these skills" (p. 11). In this case, the class was coordinated by the collaborative efforts of both faculty and librarians in order to improve student research skills.

IL instruction is also an integral part of the curriculum at Trinity University, where both faculty and librarians assess students' IL skills collaboratively, using a rubric model (Oakleaf, Millet, \& Kraus, 2011). The IL rubric was developed cooperatively by librarians, faculty, staff, and administrators through a series of workshops and is being integrated into campus-wide teaching and assessment activities. The rubric is intended to be used for a number of 
purposes, including as a tool "to track student learning across time and multiple programs on a campus level” (p. 836).

The studies discussed thus far illustrate the clear need for increased collaboration between faculty members and librarians. These examples also exemplify the vital role that librarians play in helping to bridge the gap in understanding between faculty members and students with regard to their differing approaches to research. These two recurring issues may be addressed within the context of workshops, courses, and programs that are designed and implemented collaboratively by faculty and librarians using a student-centered approach. One possible approach is to use a stratified course-integrated model as a pedagogical framework for developing IL instruction.

\section{The Stratified Course-Integrated Approach}

The stratified course-integrated approach integrates information-seeking and evaluative skills into the course content. The research paper process is thereby altered so that all students work on a specific component of an assignment at the same time, preferably for a portion of the term paper grade (Leckie, 1996). The objective of using this approach is to "reveal and deal explicitly with the expert researcher assumptions lurking at each stage of the term paper process" (p. 206). Leckie suggests that there is a wide gap between a faculty member's expectations of the undergraduate student and the student's actual ability to complete the assignment. This division is due to the faculty member's status as an expert researcher in comparison to the student's status as novice researcher. Leckie notes that there is, therefore, a disconnect that ultimately results in frustration on the part of the student, who experiences undue difficulty in completing the assignment, and on the part of the faculty member, who must read through a large pile of poorly-researched and potentially poorly-written student papers.

In addition to the concerns facing the knowledge divide between faculty members and students, the traditional research assignment also creates additional work for the academic librarian, who must work with the students to accomplish the goals that have been predetermined by the faculty member, often without consulting with librarians (Leckie, 1996). If the stratified methodology is used, there is a greater emphasis on collaboration between faculty and librarians. Rather than solely serving as a resource for students, the academic librarian is considered a "bibliographic instruction mentor" (p. 207) to faculty members. In this sense, then, the librarian's role is to support, assist, and encourage the faculty member with respect to integrating IL instruction into a course. Leckie proposes that the responsibility for introductory bibliographic instruction be shifted to the faculty member, who is able to place the instruction firmly within the context of the discipline. The librarian, then, is no longer considered the sole provider of library- 
based research skills. Therefore, unlike bibliographic instruction in which skills might be presented in an abstract sense, the instruction provided by the faculty member would be highly relevant to the class and would enhance the curriculum content.

Leckie's (1996) model includes six stages of stratification, as follows:

- Narrow the topic;

- Understand and use the popular literature;

- Demystify scholarly research;

- Find and use the scholarly literature;

- Understand legitimate shortcuts; and

- Develop a strategy for the completion of the research paper.

Leckie describes the process of progressing through these stages as a combination of completing short written assignments, receiving feedback, and participating in follow-up discussions during class. It is hoped that students will gradually hone their research topic and findings as they learn more about the research process from this type of feedback-rich instruction. The entirety of the body of work developed through this progression is then assembled and repackaged as a high quality culminating research paper.

\section{Meeting Competency Standards with a Stratified Approach}

Leckie's (1996) six-stage stratification model's value as a framework for organizing IL instruction is made clear when it is examined alongside the Association of College and Research Libraries' (ACRL) set of broad standards, observable performance indicators, and specific outcomes for assessing an individual's IL competence. These IL competency standards are frequently used as a guide in assessing students' IL skills. The Appendix contains a presentation of how the six stages of stratification and five ACRL standards may be combined.

The competency standards developed by the ACRL (2000) provide an excellent tool for instructors to use when assessing the IL levels of individual students. These standards were developed out of an effort to pay heed to one of the key missions of higher education institutions: to develop lifelong learners. The need for a set of standards resulted in part from the plethora of new information technologies and online information sources in the digital age, as well as the increasing complexity of the information environment (Head, 2008).

IL competency assessment may be conducted by measuring students' abilities and matching these abilities to the specific performance indicators. In order to ease the educator's task in designing and developing a curriculum based on these standards, the Standards Toolkit (American Library Association, 2011) provides a set of tools through a web site developed for this purpose. These tools include an introduction to each of the standards as well as practical examples of 
the performance indicators and outcomes. In addition, the website includes instructions for using and adapting the standards for use with different learning objectives.

In order to assess the potential application of stratification in courseintegration IL instruction, an undergraduate course-integrated workshop that demonstrates use of a stratified course-integrated teaching approach was observed. Considerations were given to how the workshop handles issues relating to facultylibrarian collaboration and to bridging the knowledge gap between faculty members and students.

\section{Methodology}

Qualitative research methods were used for data collection and analysis. Research activities included non-participant observation of a single IL instruction workshop, and pre- and post-workshop interviews with the workshop instructor, "Anna" (all participants are given pseudonyms and all quotations are transcribed verbatim), an Instruction and Reference Librarian. The interviews were conducted to gather information about the workshop's context and to explore librarian perspectives on IL instruction, faculty collaboration, and student learning.

The observed instruction session is part of a course for third-year Materials Science and Engineering (MSE) students at a large urban university. This specific workshop was selected because it serves as an example of the type of feedback-rich environment that is a core element of the stratified courseintegrated model. The course in its entirety is not included in this article's analysis; rather, this article focuses on providing a detailed analysis of the single observed workshop, with specific examples noted in support of the two main themes discussed in the literature review: the impact of faculty-librarian collaboration and the librarian's challenge of bridging the gap between faculty and student understanding of (and ability to participate in) the research process. This observation is, therefore, intended to serve as an introductory exploration of potential uses of a stratified approach rather than an assessment of the stratified course-integrated model in practice.

The MSE course is held over a single semester and is required for all students in their sixth semester of the undergraduate program. Students attend one hour of lectures and one hour of tutorial per week, in addition to library workshops. The coursework consists chiefly of planning and delivering a research

proposal. Student course objectives are to gain in-depth knowledge of a specific area of work within the broader MSE discipline; to read technical materials that will allow students to advance in the discipline; to organize, write and present about the ideas of the discipline using university-level sophistication and clarity; and, to present clear, well-organized technical presentations. The main focus of 
the class, therefore, is to help students develop a solid foundation of research skills as well as an appropriate level of understanding of scholarly discourse to enhance their writing skills. The work they complete in this class prepares the students for their fourth-year culminating assignment in which they will conceive, design, and carry out an original research project.

Attendance at the observed workshop is required for successful completion of the MSE course. Participation is ensured because a small percentage of the students' grade on the research assignment is reserved for two short exercises that are completed and submitted to Anna during the workshop. Prior to the session, students had already submitted a draft proposal for researching a specific topic. The purpose of the library workshop was to teach the students how to begin the process of researching their topic. In the week following the workshop, the students were required to submit a revised research proposal based on their preliminary searches. The students' completed workshop exercises were to be delivered with comments from Anna to the faculty member so that students' progress on their research assignments could be assessed and feedback provided before they moved on to the next stage of their work.

The observed instruction session was held in the instruction lab of a Sciences and Health Sciences library. In addition to Anna, there were 28 students and two teaching assistants in attendance; the faculty member was not present. One of the teaching assistants sat at the back of the class and the other sat ane of the computers in the middle of the instruction lab. The workshop was 50 minutes in duration. There were 24 computer stations in the lab, so some students shared computers while others worked individually. The instruction session was observed without the author's participation, although the author's presence was known and obvious. Observations were recorded in a non-structured way (i.e., no specific rubric was adhered to as a guide). Interviews took place both in person at Anna's workplace and through e-mail communication. The in-person interviews were unstructured; follow-up questions were posed via e-mail.

The observation and both interviews were held between September and October 2011. Because this article centers on both librarian-faculty and librarianstudent relationships, interview questions focused on the librarian's interactions and collaborations with both faculty and students.

\section{Findings and Analysis}

\section{Instruction Session: Organizational Structure}

The instruction session was timed so that the students had already formulated a potential research topic but had not yet begun searching for relevant articles in the 
literature. Thus, the students were in Stage 1 of Leckie's (1996) model ("narrow the topic").

Anna articulated four goals for the instruction session. At the end of the session, students would have learned how to:

- $\quad$ understand the difference between primary and review articles and be able to recognize and differentiate them using citations and/or full text;

- be able to construct simple searches for known items in Scopus and Compendex databases;

- be able to construct a search using the Compendex database to find review articles specifically; and

- be able to construct a simple Boolean topic search using the Compendex database.

Thus, the information covered during the session briefly touched on all six of Leckie's (1996) stages of stratification: narrowing a topic; understanding and using popular literature; explaining scholarly research; finding and using scholarly articles; understanding legitimate shortcuts; and developing a research strategy. The workshop was presented in three separate segments. Each segment was roughly fifteen to twenty minutes in length and concluded with an exercise completed either in a group or individually.

Part I: Definitions (group exercise). Anna began the instruction session by asking the students if they were familiar with terminology such as primary literature, secondary literature, review article, and peer-reviewed article. She asked questions about each term, called on volunteers, and engaged the students in order to assess their prior knowledge and maintain interest. For the group exercise, the students were randomly divided into groups based on their seating arrangements and each group was given a sample article. The students were required to determine whether the article was an example of a primary or secondary review article and had to be prepared to explain how they reached that decision. Anna let the students work in groups for about five minutes and then a spokesperson from each group reported their answers. Again, a great deal of comments and positive feedback was given to the students as they provided answers.

This section of the workshop focuses on the students' ability to demonstrate ACRL Standard One: "The information literate student determines the nature and extent of the information needed."

Part II: Peer-reviewed articles (individual exercise). The next stage of the workshop was devoted to learning how to determine if a particular journal is peer-reviewed by looking up the journal name using Ulrich's Periodicals Directory. Anna demonstrated the steps by projecting her computer to the 
overhead screen and explaining the process as she completed a sample search. She pointed at relevant sections on the overhead screen as she spoke and then asked the students to complete an exercise individually.

This written exercise required the students to log on to the Scopus database, search for one of the five articles listed in a handout, determine whether the article was a review article or primary article, and explain why they reached the answer they did. The students were given five or six minutes to complete the exercise without consulting one another. Anna walked around the room, checked in with each student at least once, and answered questions that were posed to her. This exercise was the first document to be submitted to Anna for delivery to the faculty member.

The completion of this written exercise helps the students achieve the competency outlined in ACRL Standard Two: "The information literate student accesses needed information effectively and efficiently."

Part III: Developing a search strategy (individual exercise). This part of the workshop was spent discussing how to search for articles using the Compendex database. This section incorporated lecture, presentation slides, and live computer demonstration projected to the overhead screen. Anna's discussion included the importance of developing a high quality search strategy by breaking a topic into three separate concepts, and by including keywords, synonyms, wildcards, and Boolean operators in searches.

The students then completed a written exercise over the final ten minutes of the workshop. This exercise required students to apply the search techniques that had been taught in this final section of the workshop. First, students were to take a sample topic and break it into three distinct concepts. Next, the students were instructed to use synonyms, wildcards, and Boolean operators to create three potential search strings, and to test those search strings using the Compendex database. This written exercise was the second document to be submitted to Anna for delivery to the faculty member.

The completion of this written exercise helps the students achieve the competency outlined in ACRL Standard Two: "The information literate student accesses needed information effectively and efficiently."

Because this workshop was aimed at assisting students during the initial stages of work on their research project, only the first two ACRL standards are pertinent. The instruction session briefly touched on all six of Leckie's stages of stratification, but each stage was covered minimally, as it would have been impossible to give in-depth coverage to each stage during a 50-minute instruction session. 


\section{Cooperative Collaboration}

Interviews with Anna revealed evidence of cooperative collaboration. She prepared for the session by consulting with the faculty member who teaches the MSE course. She has worked with this particular faculty member on this specific class for the past two years and has worked with the faculty member on other classes as well, so they have a history of collaboration. This fits the model of cooperative collaboration espoused thus far as the ideal environment in which to successfully implement IL instruction.

Another example of collaboration that was observed during the session involved an incident wherein a student asked a question about the difference between review articles and primary articles. Anna attempted to answer the question, but after a couple of minutes of continued questioning and explanation, the student did not seem to be gaining any clarity from the discussion. At that point, "Noah," the teaching assistant sitting in the center of the class, interjected in order to provide examples from the literature that illustrate the differences. The student appeared to finally grasp the difference between the two types of literature and Anna was able to move on with the lesson. At the conclusion of the workshop, Noah approached the student and repeated the detailed explanation. He ensured that the student genuinely understood the difference between review articles and primary articles. Anna had a quick conversation with Noah to thank him for helping the student. The input from the teaching assistant during the workshop was not interpreted as an interruption or as Noah undermining Anna's authority. Rather, his assistance was welcomed because it allowed the session to proceed without Anna having to spend an undue amount of time resolving a single student's difficulty comprehending the material.

\section{Bridging the Gap}

Anna has taught the MSE workshop for a number of years and is constantly revising and refining her teaching plan in order to meet not only the faculty member's needs, but also those of the students. This student-centered approach of developing an instruction session corresponds with what has been noted in the literature about librarians who base the quality of their instruction on the success of their students. During the post-workshop interview, Anna noted that many of the students appeared to have blank looks on their faces during the Boolean searching segment. She speculated that terminology may have been unfamiliar or, perhaps, forgotten by students who may have covered Boolean concepts in firstyear IL instruction sessions. She planned to revise this portion of the workshop for future presentations. 
The purpose of the workshop was to provide students with introductory research skills. Students could use the information gleaned from the instruction session to begin researching their selected topic using library resources. The session, therefore, helped the students develop the competencies described in the ACRL standards, primarily Standards 1 ("determine the nature and extent of the information needed") and 2 ("access needed information effectively and efficiently"). Intrinsic motivational strategies were employed since the learning interaction coincided with an immediate need. The step of completing and submitting the written exercises at the workshop would be instructive and allow both the librarian and the faculty member to determine which students were on the right track to understanding the course material. In addition, these activities helped the students to assess their own level of competency. Finally, participation in this workshop placed the students in an environment where they had access to a resource able to assist them in refining their topic and in improving their search strategies as they developed their research proposals.

\section{Challenges in Implementing the Stratified Course-Integrated Approach}

Adopting a stratified course-integrated approach to library instruction may be beset with a certain set of challenges. Leckie (1996) and Leckie and Fullerton (1999) note four major issues related to this type of instruction: the increased workload and effort associated with marking additional assignments and providing extra feedback to each student; the need to devote further class time to IL instruction which may involve decreased time spent on covering curricular content; the challenges inherent in implementing this type of instruction with large class sizes; and the possibility that effective IL instruction is time- and discipline-specific.

With regards to the first point-increased marking and feedback-the benefits from receiving increased feedback may rectify the problem of students feeling confused and overwhelmed by the research process. As noted in the Literature Review, students cannot learn the discourse of a discipline and the process of conducting and writing about research unless they are explicitly taught how to participate in this type of scholarship through faculty or librarian intervention. Therefore, additional marking should not be viewed as a negative component of instruction, but rather a way for experts in the field to share knowledge with the novices who, with training, will become the next generation of experts.

The second challenge relates to increasing the amount of course-integrated IL instruction at the expense of covering course content. The maxim "Give a man a fish and you feed him for a day; teach a man to fish and you feed him for a lifetime" is applicable. Faculty should not simply aim to deliver information to 
students. Instead, faculty should be teaching students how to participate in the discourse of the students' chosen discipline and how to read and evaluate the literature on a given subject. This is where faculty-librarian collaboration is essential, as the academic librarian is well-versed in providing this type of instruction. As Leckie (1996) notes, "I would much rather look at 40 research papers that were relatively well done than 40 that were awful, so I would consider the time spent on research skills as a good investment from a pedagogical point of view" (p. 206).

The third issue is that it can be difficult to coordinate this type of instruction for large class sizes. The benefit of providing this type of instruction to upper-year undergraduate classes is that class size is generally smaller than in first- or second-year classes. Thus, implementation strategies requiring additional support from teaching assistants or other librarians would likely be unnecessary.

A fourth issue is suggested by research demonstrating that different types of IL instruction may be required for different disciplines and that librarians should take a flexible pedagogical approach. For example, survey and interview research conducted by Leckie and Fullerton (1999) found the highest levels of support for first-year course-integrated instruction by arts and social sciences faculty, whereas faculty in the sciences and engineering are more supportive of the course-integrated approach for upper-level courses. Therefore, it may be beneficial to complete a deeper exploration of faculty attitudes and disciplinespecific IL instruction initiatives in order to determine the most appropriate and effective application of the stratified course-integrated model in the undergraduate setting.

\section{Conclusion}

Many undergraduate students are unfamiliar with the process of researching a topic effectively, yet they are frequently assigned the task of writing a research paper without being given the necessary preliminary instruction. An introduction to the research process is necessary for students to successfully complete these assignments. This type of instruction may be most effective in a stratified, courseintegrated format in an effort to maintain relevancy for students and to meet these students at their point of need. In addition, this type of instruction may be the most effective preparation for succeeding in future complex academic pursuits, such as theses, culminating projects, and graduate-level work. It is readily apparent that the original research in this article is extremely limited in scope. However, this initial exploration into IL instruction models considered in tandem with the literature review suggests the merits of a deeper look at potential applications of the stratified course-integrated model at the upper-year undergraduate level. In order for students to achieve success in research 
assignments, faculty-librarian collaboration is key, and faculty members should provide instruction that helps novice researchers develop knowledge of the discourse of their chosen discipline.

The inclusion of stratified course-integrated instruction in upper-division courses may be an excellent opportunity for librarians and faculty members to engage in cooperative IL instruction. In addition, this can be a valuable way to ensure students remain connected to the idea of the library as a valuable resource. It is essential for students to develop the concept that IL instruction is not merely an introductory "How to use the library" workshop undertaken during their first year of undergraduate study. Rather, IL should be considered a key part of lifelong learning for all individuals. Educational institutions increasingly prioritize the value of IL instruction in an undergraduate education, and, as was noted in this article, LIS research includes a number of recent examples of large-scale IL programs being implemented at the undergraduate level.

Further research in this area could focus on applying stratified courseintegrated instruction to upper-year undergraduate classes in various disciplines to determine the impact of this type of IL instruction on student success and which disciplines are better suited to this type of instruction. It would also be helpful to conduct survey research to determine student interest in this type of instruction and to determine how best to implement course-integrated IL instruction in the curriculum to maintain a student-centered focus. As IL instruction becomes further ingrained in the undergraduate curriculum, the integration of these skills within the context of assignments and other coursework is likely. It is, therefore, essential for faculty members and academic librarians to embrace a culture of cooperative collaboration in order to further advance the development of undergraduate research skills. This is vital not only for the purposes of applying these skills toward undergraduate theses or other culminating experiences, but to develop a pattern of lifelong learning on the part of these future scholars and practitioners. 


\section{References}

American Library Association. (2011). Standards toolkit. Retrieved from http://www.ala.org/ala/mgrps/divs/acrl/advocacy/infolit/standards/standard stoolkit.cfm

Association of College and Research Libraries. (2000). Information literacy competency standards for higher education. Chicago: Association of College and Research Libraries. Retrieved from http://www.ala.org/ala/mgrps/divs/acrl/standards/informationliteracycomp etency.cfm

Bodi, S. (2002). How do we bridge the gap between what we teach and what they do? Some thoughts on the place of questions in the process of research. Journal of Academic Librarianship, 28(3), 109-114. doi:10.1016/S00991333(01)00302-0

Farber, E. (1999). Faculty-librarian cooperation: A personal retrospective. Reference Services Review, 27(3), 229-234. doi: $10.1108 / 00907329910283151$

Feldman, D., \& Sciammarella, S. (2000). Both sides of the looking glass: Librarian and teaching faculty perceptions of librarianship at six community colleges. College \& Research Libraries, 61(6), 491-497. Retrieved from http://crl.acrl.org/

Given, L. M., \& Julien, H. (2005). Finding common ground: An analysis of librarians' expressed attitudes towards faculty. The Reference Librarian, 43(89/90), p. 25-38. doi: 10.1300/J120v43n89_03

Gunselman, C., \& Blakesley, E. (2012). Enduring visions of instruction in academic libraries: A review of a spirited early twentieth-century discussion. Portal: Libraries and the Academy, 12(3), 259-281. Retrieved from http://muse.jhu.edu/

Head, A. J. (2008). Information literacy from the trenches: How do humanities and social science majors conduct academic research? College \& Research Libraries, 69(5), 427-446. Retrieved from http://crl.acrl.org/ 
Julien, J., \& Pecoskie, J. (J. L.). (2009). Librarians' experiences of the teaching role: Grounded in campus relationships. Library \& Information Science Research, 31(3), 149-154. doi: 10.1016/j.lisr.2009.03.005

Kolowich, S. (2011, August 22). What students don't know. Inside Higher Ed. Retrieved from http://www.insidehighered.com/news/2011/08/22/erial_study_of_student_ research_habits_at_illinois_university_libraries_reveals_alarmingly_poor_ information_literacy_and_skills

Leckie, G. J. (1996). Desperately seeking citations: Uncovering faculty assumptions about the undergraduate research process. Journal of Academic Librarianship, 22(3), 201-208. doi: 10.1016/S00991333(96)90059-2

Leckie, G. J., \& Fullerton, A. (1999). Information literacy in science and engineering undergraduate education: Faculty attitudes and pedagogical practices. College \& Research Libraries, 60(1), 9-30. Retrieved from http://crl.acrl.org/

Mahaffy, M. (2006). Encouraging critical thinking in student library research: An application of national standards. College Teaching, 54(4), 324-327. doi: 10.3200/CTCH.54.4.324-327

McGuinness, C. (2006). What faculty think: Exploring the barriers to information literacy development in undergraduate education. Journal of Academic Librarianship, 32(6), 573-582. doi: 10.1016/j.acalib.2006.06.002

Minchow, R. L., Pudlock, K., Lucas, B., \& Clancy, S. (1993). Breaking new ground in curriculum integrated instruction. Medical Reference Services Quarterly, 12(2), 1-12. doi: 10.1300/J115V12N02_01

Oakleaf, M., Millet, M. S., \& Kraus, L. (2011). All together now: Getting faculty, administrators, and staff engaged in information literacy assessment. Portal: Libraries and the Academy, 11(3), 831-852. Retrieved from http://muse.jhu.edu/

Raven, M. (2012). Bridging the gap: Understanding the differing research expectations of first-year students and professors. Evidence Based Library and Information Practice, 7(3). Retrieved from http://ejournals.library.ualberta.ca/index.php/EBLIP/index 
Simmons, M. H. (2005). Librarians as disciplinary discourse mediators: Using genre theory to move toward critical information literacy. Portal:

Libraries and the Academy, 5(3), 297-311. Retrieved from http://muse.jhu.edu/

Stowe, B. (2011). "I can't find anything": Towards establishing a continuum in curriculum-integrated library instruction. Reference Services Review, 39(1), 81-97. doi: 10.1108/00907321111108132

Tucci, V. K. (2011). Faculty/librarian collaboration: Catalyst for student learning and librarian growth. Science \& Technology Libraries, 30(3), 292-305. doi:10.1080/0194262X.2011.596792 
Appendix

The Stratified Course-Integrated Model of Information Literacy Instruction and Corresponding ACRL Standards

\begin{tabular}{|c|c|c|c|}
\hline \multicolumn{2}{|r|}{ Leckie's (1996) 6-Stage Model } & \multicolumn{2}{|r|}{ ACRL IL Competency Standards } \\
\hline 1 & Narrow the topic & 1 & $\begin{array}{l}\text { Determines the nature and extent of the information } \\
\text { needed }\end{array}$ \\
\hline \multirow[t]{2}{*}{2} & \multirow{2}{*}{$\begin{array}{l}\text { Understand and use the } \\
\text { popular literature }\end{array}$} & 2 & Access needed information effectively and efficiently \\
\hline & & 3 & $\begin{array}{l}\text { Evaluate information and its sources critically } \\
\text { Incorporates selected information into knowledge base } \\
\text { and value system }\end{array}$ \\
\hline 3 & $\begin{array}{l}\text { Demystify scholarly } \\
\text { research }\end{array}$ & 3 & $\begin{array}{l}\text { Evaluate information and its sources critically } \\
\text { Incorporate selected information into knowledge base } \\
\text { and value system }\end{array}$ \\
\hline \multirow[t]{2}{*}{4} & \multirow{2}{*}{$\begin{array}{l}\text { Find and use the scholarly } \\
\text { literature }\end{array}$} & 2 & Access needed information effectively and efficiently \\
\hline & & 3 & $\begin{array}{l}\text { Evaluate information and its sources critically } \\
\text { Incorporate selected information into knowledge base } \\
\text { and value system }\end{array}$ \\
\hline \multirow[t]{2}{*}{5} & \multirow{2}{*}{$\begin{array}{l}\text { Understand legitimate } \\
\text { shortcuts }\end{array}$} & 2 & Access needed information effectively and efficiently \\
\hline & & 5 & $\begin{array}{l}\text { Understand many of the economic, legal, and social } \\
\text { issues surrounding the use of information } \\
\text { Access and use information ethically and legally }\end{array}$ \\
\hline 6 & $\begin{array}{l}\text { Develop a strategy for } \\
\text { completing a research paper }\end{array}$ & 4 & $\begin{array}{l}\text { Individually, or as a member of a group, use information } \\
\text { effectively to accomplish a specific purpose }\end{array}$ \\
\hline
\end{tabular}

Note. ACRL = Association of College and Research Libraries. Adapted from "Desperately seeking citations: Uncovering Faculty Assumptions about the Undergraduate Research Process" by G. Leckie, 1996, Journal Of Academic Librarianship, 22(3), p. 206 and "Information Literacy Competency Standards for Higher Education" by the Association of College and Research Libraries, 2000. 